\title{
Examining the five-stage e-moderating model: designed and emergent practice in the learning technology profession
}

\author{
Bernard Lisewski* and Paul Joyce*** \\ *University of Salford, UK, **UMIST, UK \\ email:b.lisewski@salford.ac.uk.p.joyce@umist.ac.uk
}

This paper highlights the need for learning technologists to establish their 'academic legitimacy' within the complexities of online learning and teaching practice. Frameworks such as the 'five stage e-moderating model' can be useful in developing the knowledge base but there are dangers in them becoming too reified within an increasingly commodified higher education (HE) environment. The paper calls for greater professional reflexivity and contestation within learning technology practice and concludes by inviting the ALT-J readership to engage in a critical debate with regard to these issues.

\section{Introduction}

The JCALT report, Career Development of Learning Technology Staff, highlighted 'a lack of academic legitimacy' (Beetham, Jones and Gornall, 2001: 6 ) as being a problem for individuals and the learning technology profession as a whole. Similarly, Oliver (2002: 20) has emphasized that if learning technologists 'cannot establish their credentials with the academics, then it is unlikely that fruitful dialogue will follow, since the collaborator will see them as a service provider rather than an expert'.

To achieve the right balance between the pedagogical approach and the appropriate use of a given technology within the prevailing resource and cultural environment (Beetham et al., 2001: 24), learning technologists require effective tools, processes and discourses to establish their professional identity. From the 'world of corporate capital and its accompanying ideology' (Taylor, Barr and Steele, 2002: vii) come tools such as virtual learning environments. Although these have all-encompassing toolsets, are easy to use and can be bought 'off the shelf', they arrive with the dangers of an implicit pedagogical bias, 
the 'appearance' of innovation and the hegemony of standardization (Conole, Sharp and Beharrell, 2002).

As well as adopting and using these toolsets effectively in establishing their professional and academic presence, learning technologists need to develop a knowledge base which, in particular, informs the process of teaching and learning online. Further to this is the challenge of catering for the 'wide spectrum of capability' (Barker, 2002: 3) of learners that is required across different modes of online educational provision.

In recent years, the tools, knowledge base and discourse of the learning technology profession has been bolstered by the appearance of conceptual paradigms such as the 'five stage e-moderating model' (Salmon, 2000) and the new mantra of 'communities of practice' (Wenger, 1998). This paper will argue that, although these frameworks are useful in informing and guiding learning technology practice, there are inherent dangers in them becoming too dominant a discourse. The main focus will be on the 'five stage e-moderating model' as providing an exemplar of a discourse which is in danger of forming a 'grand narrative' (Lyotard, 1984) or totalizing explanation of how to design and deliver online training programmes. (Recent uncritical citations of the Salmon model across very different contexts include: Alexander and Boud, 2001; Arbaugh and Duray, 2002; Barker, 2002; Bennett and Marsh, 2002; Flecknoe, 2001; Forman, Nyatanga, and Rich, 2002; Forsyth, 2002; Good, 2001; Hughes and Daykin, 2002; Loveless, Williams, and Kutnick, 2000; Macdonald, 2002; Slaouti, 2000; and Thorpe, 2002.) In doing so, it thereby simultaneously helps to shape the agenda for legitimizing certain aspects of learning technology practice.

\section{The five stage e-moderating model as a dominant discourse}

In essence, this paper is a response to an evaluation of a recent online e-moderating training course run jointly by Salford and Huddersfield Universities within the framework of the 'five-stage e-moderating model' (Salmon, 2000). Both institutions 'delivered' the course to the twenty three participants using the Blackboard virtual learning environment (VLE) conferencing facilities. The participants' experiences on the programme were evaluated using virtual ethnography (Hine, 2000), focus group and interview methodologies. One of the emergent features of the evaluation was the status which these types of course (and their embodied models) have within teaching and learning technology practice and the ways in which they impact on, and reflect, professional identity.

There were several reasons for undertaking the collaborative project. Firstly, we held a strong belief that it is important for potential online tutors to experience fully online teaching and learning interaction aimed at developing an advanced state of empathy with their prospective learner communities. This motive is strongly echoed by Wills, Nouwens, Dixon and Lefoe (1997: 2):

Staff should be able to put themselves into the learner's shoes and actively experience the learning environments that are advocated for their students. In order to mainstream these experiences for students, they need to be mainstreamed for staff professional development. Only when staff are comfortable with using a variety of delivery methods will they be able to incorporate them successfully in their own teaching. 
Secondly, the 'five-stage e-moderating model' seemingly offered a useful paradigm for structuring, pacing and situating the developmental experiences of the course participants. It was presented as a usable 'off the shelf' product with an inbuilt staged pedagogical approach to teaching and learning collaboratively online through computer mediated conferencing (CMC), as illustrated in Figure 1.

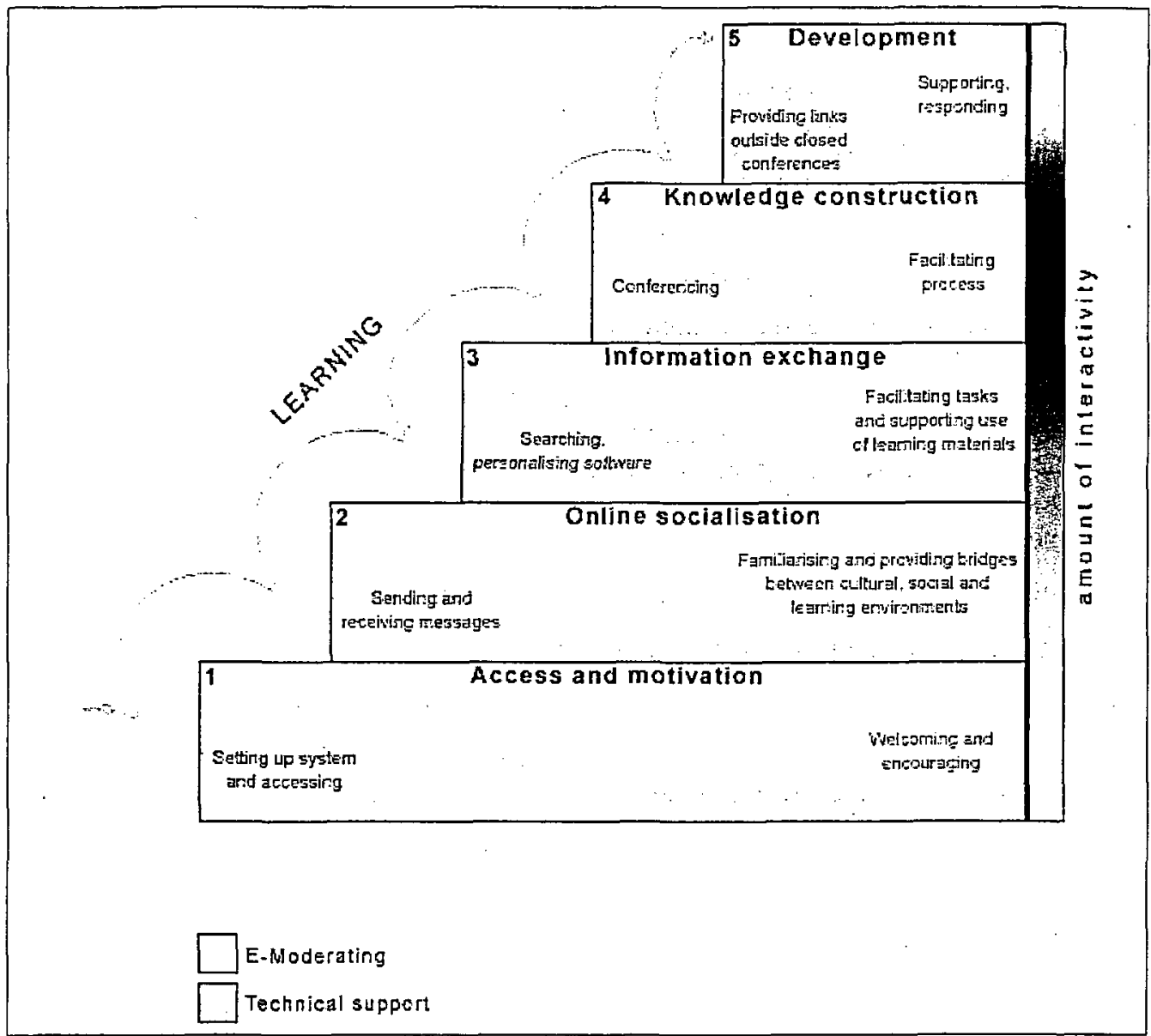

Figure 1: The five stage e-moderating model of teaching and learning online through computer mediated conferencing (reproduced by permission of Gilly Salmon)

The reflexive nature of the course - an online course about e-moderating online courses also highlighted and amplified certain teaching and learning practice issues. For example, although acknowledging that online collaboration can considerably enhance the learning experience, Laurillard (2002) argues that, in collaborative learning, structure and staged timetabling reduces flexibility, compromising 'normal life' which can lead to feelings of guilt and stress as part of the collaborative process.

The purpose of the course was to produce e-moderators, or at least to sensitize practitioners to the issues surrounding e-moderating online. The process by which this 
took place was through a series of stages that increasingly built up greater understanding of e-moderation as both e-moderators and as participants on the course. This was facilitated by the use of 'e-tivities' (structured tasks) and reflective processes that corresponded to each of the five stages.

The first thing to be said about the evaluation findings is that many of the participants viewed their participation in the course in a relatively positive light. The main reason for this was the perceived beneficial experience of 'being on the other side' of the e-learning process. As two of the participants stated:

In spite of all my negative comments I did enjoy the course . . I think anything that questions what you do is extremely useful.

We should have a policy at the University that no one can put something online until they've done an e-moderating course.

However, as one of the previous comments intimates, whilst experience of the course was thought to be beneficial, the course design itself was viewed less favourably. Many thought it to be too rigid and restrictive and the five-stage/five-week structure was considered to be problematic. The demands placed on the participants by e-tivities were unevenly spread across the five weeks. Moreover, the external tutors discouraged deviations from the structure of the course. As new ideas arose, it became increasingly difficult to change the focus of activity and explore new avenues of thought. A summary of the key findings is presented below:

- The five-week timescale (a week allotted to each of the stages) was too restrictive.

- Having fallen behind it was hard to catch up.

- It was too difficult to change the focus of the course as new ideas arose.

- The balance of e-tivities over the five weeks/stages was problematic - too many timeconsuming e-tivities in the later stages.

- The course did not take into account individual learning styles.

All the evaluation feedback concerns appear to be symptomatic of a deeper tension within the 'five-stage e-moderating model'. The rigidity with which the structure was applied did not sit easily with the demands of the course to be reflective about individual online teaching and learning practice. It is paradoxical that a course that presents itself as embodying the idea of reflective practice does not seem to be able to employ the same methodology in reflecting upon the efficacy, dominance and legitimacy of the five stage emoderating model itself. This lack of flexibility and reflexivity is indicative of our deeper concerns about the evolution of the learning technology profession in employing such frameworks in its practice.

\section{Reification of pedagogic frameworks}

Prior to pursuing this issue further, there is a need to introduce the process of reification in examining the relationship between designed teaching frameworks and the emergent learning which occurs. In this regard, Wenger (1998: 267) has emphasized that what matters is the 'interaction of the planned and the emergent - that is, the ability of teaching and learning to interact so as to become structuring resources for each other'. 
Wenger asserts that effective educational practice revolves primarily around forming 'identities and modes of belonging' rather than in information delivery and skills acquisition. In negotiating meaning and forming identity within any learning situation, there lies an ongoing organic inter-relationship between the dualities of reification and participation. Whilst the latter involves the learner in doing and interacting rather than acting passively, the former refers to the process of giving form to experiences by producing objects that codify practice. As Kirkup (2002: 185) states:

Reification is what happens when meaning is projected or solidified through the production of an object, such as a book, a set of rules, a code of practice, a procedure, a tool. All these things 'congeal' meaning/knowledge into a fixed form.

Wenger (1998: 58) outlines the dangers of such processes taking hold:

The power of reification - its succinctness, its portability, its potential for physical persistence, its focusing effect - is also its danger [. . .] the tool can ossify activity around its inertness. Procedures can hide broader meanings in blind sequences of operations. And the knowledge of a formula can lead to the illusion that one fully understands the processes it describes.

Our concern here is with how the 'five-stage e-moderating model' has become too reified as a type of product in informing and guiding learning technology practice. There is a danger that such objectified models become 'off the shelf', 'one size fits all' products that are seemingly transferable and usable across widely differing teaching and learning contexts and as such become unquestionable components of the learning technologist's knowledge base. As Wenger (1998: 65) notes, if one is exposed to too much reification, 'there may not be enough overlap in participation to recover a co-ordinated, relevant, or generative meaning'.

However, there are clearly organizational benefits to reification. If certain elements of professional practice have been reified to the point of standardization or even to become a commercial product (as the e-moderating course appeared to be), then they may be the safest option when deciding on future organizational strategies aimed at improving learning technology practice. The existence of an established 'off the shelf' product acceptable to professional peers saves time in having to devise bespoke solutions to perceived problems. It is understandable that time-constrained academics may demand these products, but alongside them comes the need to develop new pedagogies, new teaching identities (Bayne, 2002) and more collaborative working practices underpinned by appropriate support mechanisms, organizational frameworks and realistic resource allocations. In effect, what is required is a 'reconceptualisation of academic practices' (Land, 2000: 22) given that, as Oliver (2002: 20) asserts, learning technologists are involved in the 'core work of collaborative curriculum development'.

Furthermore, the danger is that in relying too much on 'off the shelf' solutions, such reified models become the dominant structural paradigm in informing and defining professional identity and practice. Interestingly, Jean Lave - long-time colleague of Wenger - has recently expressed similar concerns about how the concept of 'communities of practice', in acting as a structural metaphor for organizing educational practice, has been taken up and imposed in a top-down way in educational settings as a sort of model of 'good pedagogy' (Lea and Nicholl, 2002: 10). 


\section{Informing and guiding online teaching and learning practice}

The experience of our course participants highlights the dangers of taking a framework such as the five-stage model and using it as a template or object, that is, allowing it to act as a 'grand narrative or totalizing explanation' for designing the online teaching and learning environment when using CMC. This model emerged from an action research methodology within the context of the UK Open University Business School's online programmes. Using content analysis and focus group work, the model 'provided a set of constructs that could be tested as well as a basis for later online induction and training programmes' and 'applies to all CMC software' (Salmon, 2000: 23 and 26).

However, George and Cowan (1999: 20) draw a comparison between action research which is 'restricted to particular subjects, teachers and situations . ... and educational research which pushes what is known about education, and hence contributes to the enhancement of informed professional practice'. This distinction raises the question of whether the fivestage model offers general transferability of educational practice across widely differing teaching and learning contexts and, as such, significantly contributes to, and legitimizes, important pedagogic processes within the learning technology profession.

The question for learning technology practitioners in seeking to address contemporary teaching and learning challenges is how to obtain the appropriate duality between participation and reification. Or perhaps, more pertinently, how to strike the balance between professional legitimacy and autonomy with reification. Although the emoderating course experience described earlier is just a single example, it does fit into a recognized pattern of activities within the profession. The preponderance of uncontested models (such as the Salmon model or the ongoing VLE/MLE determinism) and voguish theorizing (Wenger included) have much in common with the faddish behaviour in other disciplines, business and management studies being the most obvious. The problem is: what does this imply about the present state of learning technology practice? The dominance of reified 'off the shelf' solutions and theoretical faddishness sits uneasily with disciplinebased notions of reflective practice and concepts such as the 'learning organization'. Is this a case of a new, immature profession finding its feet and establishing a body of knowledge and expertise that informs professional practice? Or is professional learning technology practice being driven by the need to find quick and easy solutions to the massification of the higher education experience? In many ways, these questions reflect the wider fears of the academic community with regard to the 'managerial colonization' and 'commodification' of the higher education teaching and learning process (Prichard and Willmott, 1997; Barry, Chandler and Clark, 2001; Chandler, Barry and Clark, 2002). Similarly, alongside these anxieties, Land and Bayne (2001: 8) argue that the very "ethos of the MLE can be viewed as ... essentially managerialist. It is about order, efficiency, identified outcomes and control.'

We believe that there are great dangers in too much codification and commodification in the process of explaining teaching and learning relationships, whether it be in a face-toface or an online context, especially given the need - as Ramsden (1992), Biggs (1999), Rowland (2000) and Knight (2002) emphasize - to develop teaching strategies for higher education which are aimed at 'promoting complex learning'. Ramsden (1992: 267) in particular argues: 
The development of good teaching involves a [ . . ] process of change from simple to complex, from absolute to relative, from unquestioning acceptance of authority to a search for personal meaning, from discrete techniques to the expression of skills within an ordered, yet ultimately provisional system.

Similarly, Prosser and Trigwell (1999: 168) have asserted:

Good teaching is not about applying predetermined recipes, techniques or templates to learning and teaching situations. Each learning and teaching situation is unique.

Further to this, Shulman (1987: 11), in examining the sources of the knowledge base for establishing teaching legitimacy, states:

Discovering, explicating, and codifying general teaching principles simplify the otherwise outrageously complex activity of teaching. The great danger occurs [. . .] when a general teaching principle is distorted into prescription, when maxim becomes mandate.

The esoteric, emergent and complex technical knowledge that forms the basis of professional identity within the teaching and learning relationship is not immune to being ultimately broken down into simple tasks and standardization (Freidson, 1994). It is not desirable in many pedagogic circumstances to do this, but it is not unreasonable to believe that when new forms of management discourse arise, commodification or reification of professional activity may take place. Furthermore, different forms of professional expertise may be promoted that undermine longstanding patterns of professional conduct to meet new political agendas or the challenge of newly formulated problems.

\section{Searching for 'academic legitimacy': the need for greater reflexivity. and contestation in learning technology practice}

We acknowledge that we have to be vigilant here and not throw the baby out with the bathwater in examining the role of models and frameworks in learning technology practice. Codified and commodified models can inform and guide our practice by acting as 'objectified comfort blankets' in helping to establish legitimacy for the learning technology profession by building up its knowledge base. However, there are dangers in prescription (Knight, 2002: 217), given that 'talk of complexity and contingency [. . .] combine to suggest that the quintessence of teaching eludes commodification and measurement'.

There is an immediate need to promote much greater professional reflexivity in using such models, allied to fostering more subversion, contestation and appropriation of these frameworks within local contexts - particularly given an increasing 'off the shelf' managerialist agenda. As Wenger (1998: 9) argues:

A key implication of our attempts to organise learning is that we must become reflective with regard to our own discourses of learning and to their effects on the ways we design for learning.

Even if we accept such models as the five-stage one as providing useful frameworks, should they always be represented as a set of fixed stages, phases or steps generally applicable to a wide variety of teaching and learning contexts? For example, Shulman (1987: 19), when referring to his own model of teaching - comprehension, transformation, instruction, 
evaluation and reflection - reflexively comments that 'many of the processes can occur in a different order. Some may not occur at all during some acts of teaching. Some may be truncated, others elaborated.'

Within any 'design for learning' process, one needs to strive for the correct balance between reification and participation or structure and empowerment on behalf of the learner within the local teaching and learning context. Effectively, it becomes a decision around 'when to reify and when to rely on participation' (Wenger, 1998: 265) in pursuit of the negotiation of meaning, rather than decisions about transmitting information and promoting skills acquisition.

The wider question for the learning technology profession is how it wishes to establish its 'academic legitimacy' within an increasingly dominant managerial discourse. It is evident that the profession has grown in influence and complexity in recent years (Beetham et al., 2001; Oliver, 2002). More significantly, the rhetoric surrounding changes in the organization of higher education has much in common with how the profession sees itself. The concept of the 'learning organization', often applied to higher education in terms of quality management, is a product of the same ideas of reflexive practice that can be applied to idealized professional practice. So, at least superficially, the learning technology profession shares some of the key ideals of the new managerial discourse. In addition, it has to be said that many of the critical stances against the new forms of higher education management are produced by academics and concern themselves with their loss of academic power. They say very little about alternative sources of pedagogic expertise, such as the learning technologist being viewed as a 'service provider rather than an expert' (Oliver, 2002: 20).

In many ways, the concept of 'alternative pedagogic expertise' is key to understanding the development of the learning technology profession. In order to be taken seriously as a profession, or as seriously as the profession thinks it ought to be taken, there has to be a claim made for some form of validation. What is not clear in terms of learning technology is the pathway that the profession has to follow in order to pursue this goal of validation and legitimacy. As Beetham et al. (2001: 69) point out, 'there were conflicting strategies for the (agreed) objective of raising credibility, validation and legitimacy for learning technology work'. However, what cannot be overlooked is that the very notions of validity and legitimacy within professions are not given or 'taken for granted'. The profession (or those who employ the profession) may present them as such to forestall external challenge, but the ideas of validity and legitimacy still remain highly contested and contestable. Moreover, the pathways to validation and legitimacy themselves create the discursive space that will eventually define professional practice. Claims for legitimacy by professional bodies cannot be divorced from the application of the expert knowledge they seek to regulate and dominate. Equally, professional practice cannot be viewed as separate from the concept of authority and the exercise of power. Therefore, it is clear that the route to professionalism defines practice and ultimately identity. For a new profession, such as learning technologists, the pitfalls are all too clear. In the higher education setting, the temptation is to 'go native' (Beetham et al., 2001: 69) and follow the classic path of research and self-regulation through academic journals and peer review to become a quasiacademic discipline. However, the route to legitimacy within higher education does not take place within a power vacuum: the terrain is already occupied and to some extent 
mapped by competing professional interests - political, managerial and educational. To become part of this professional milieu may mean that the pathway to validation and legitimization is not totally at the discretion of learning technologists themselves. The profession may have to align itself with one or other of the dominant professions (such as the new managerial discourse) in order to fulfil its own professional goals.

However, once again there are dangers in reification, or what Webb (1996: 109) refers to in this particular context as a process of 'credentialing' within educational development practice. As he states, 'the fear is that a drive to professionalism will lead to conformity and fear of difference, rather than contest and innovation'.

There is currently little evidence that learning technology as a profession will supplant or even equal 'academic power' in higher education, but the new pedagogic technologies, such as VLEs and MLEs and all aspects of e-learning, have become central to delivering quality mass education. The profession that mediates these technologies is ideally placed to stake a claim in the new hierarchies of power. However, there is something of a paradox, in that as stated earlier many of these technologies are highly reified. As a profession, what does this suggest about future development? The learning technology profession as a coherent body of expertise is a relatively new phenomenon, even if its practices are increasingly in demand. Will the onset of maturity bring with it a degree of autonomy of practice within higher education? Or will the profession be increasingly defined by a powerful managerial discourse and become more closely aligned to the power hierarchy, with all the benefits and prestige that ensue, but at the price of professional freedom? These are some of the questions that need to be explored empirically.

We are in agreement with Taylor et al. (2002) that, in developing learning technologists' knowledge base and 'academic legitimacy', there is a need to foster the growth of 'social processes and epistemological communities' within our professional networks.

\section{Conclusion: or is it the start?}

By using the 'five-stage e-moderating model' as an exemplar, we have attempted to highlight the dangers of adopting an over-codified, 'off-the-shelf', 'one-size-fits-all' approach to educational development, even though such adoption is understandable within an increasingly commodified higher education environment.

For a relatively new profession trying to establish itself within the academic community and culture, we need to be more self-critical of the 'body of knowledge' and practice that we are drawing upon and seeking to legitimize. For example, is the 'five-stage e-moderating model' becoming too reified to the point of commodification? A similar question could be addressed to the 'off the shelf' mentality associated with VLEs which has also become a prevailing driving force within current teaching and learning practice.

Although such toolsets can invest in us 'gravitas in the form of codified products' and virginal legitimacy amongst our peers, as a neophyte profession we need to establish a more self-reflexive, questioning, contestable and research-based ethos of practice. Perhaps, given our relative youth as a profession it is understandable that the five-stage model of online interaction has become a dominant paradigm for one area of our practice. However, this area may simply be one of many that we have yet to 'receive' and contest. 
In seeking to establish frameworks for, and pathways to, legitimacy for the learning technology profession, we recognize that an article such as this could itself become too reified to achieve these aims. Thus, rather than ending with assertions, we invite reflection and discussion through response to the following questions for learning technology practitioners:

- How comfortable are you using these types of tools, models and discourses in your professional practice?

- How should learning technologists be legitimized and identified by these tools, models and discourses?

- What does the concept of 'academic legitimacy' mean for the learning technology profession and how should it be achieved?

- Does a relatively new profession need gurus and artefacts?

- What is the knowledge construction process for the learning technology profession?

- How should we seek to establish the learning technology role given that it often seems to be 'hybrid, marginal and yet central to institutional processes of change'? (Oliver, 2002: 19)

\section{Acknowledgements}

The authors wish to thank Amy Pearson, Lisa Corley and Andrew Gold at the University of Salford for their valuable comments and structured insights. Our hearty thanks also go to the course participants from Salford and Huddersfield Universities for providing us with their illuminating feedback.

\section{References}

Alexander, S. and Boud, D. (2001), 'Learners still learn from experience when online', in J. Stephenson (ed.), Teaching and Learning Online: Pedagogies for New Technologies, London: Kogan Page, 3-15.

Arbaugh, J. and Duray, R. (2002), 'Technological and structural characteristics, student learning and satisfaction with web based courses: an exploratory study of two online MBA programs', Management Learning, 33 (3), 331-47.

Barker, P. (2002), 'On being an online tutor', Innovations in Education and Teaching International, 39 (1), 3-13.

Barry, J., Chandler, J. and Clark, H. (2001), 'Between the Ivory Tower and the Academic Assembly Line', Journal of Management Studies, 38 (1), 87-101.

Bayne, S. (2002), 'Mutability, metamorphosis and education in cyberspace', paper presented at the Ideas in Cyberspace Education (ICE) Symposium at Higham Hall, Lake District, 30 October, organized by ALT, University of Edinburgh and Queen Mary University College, Edinburgh, http://mcdept.qmuc.ac.uk/ice/.

Beetham, H., Jones, S. and Gornall, L. (2001), Career Development of Learning Technology Staff: Scoping Study Final Report, JISC Committee for Awareness, Liaison and Training Programme, http://sh.plym.ac.ukleds/effects/jcalt-project/. 
Bennett, S. and Marsh, D. (2002), 'Are we expecting online tutors to run before they can walk?', Innovations in Education and Teaching International, 39 (1), 14-20.

Biggs, J. (1999), Teaching for Quality Learning, Buckingham: SRHE/OUP.

Chandler, J., Barry, J., and Clark, H. (2002), 'Stressing academe: the wear and tear of the new public management', Human Relations, 55 (9), 1051-69.

Conole, G., Sharp, K. and Beharrell, A. (2002), Bizled: A Jigsaw of Tools to Model and Enrich Learning, proceedings of the WWW 2002 Conference, Hawaii 7-10 May, http://www2002.org/CDROM/alternatel696/.

Flecknoe, M. (2001), 'The use of virtual classrooms for school improvement', paper presented at BELMAS Annual conference, Newport Pagnell, October, http://www.leeds.ac.ukleducolldocuments/00001900.htm.

Forman, D., Nyatanga, L. and Rich, T. (2002), 'E-learning and educational diversity', Nurse Education Today, 22 (1), 76-82.

Forsyth, R. (2002), 'Making professional development flexible', Open Learning, 17 (3), 251-8.

Freidson, E. (1994), Professionalism Reborn: Theory, Prophecy and Policy, Cambridge: Polity Press.

George, J. and Cowan, J. (1999), A Handbook of Techniques for Formative Evaluation: Mapping the Student's Learning Experience, London: Kogan Page.

Good, M. (2001), 'On the way to online pedagogy', in J. Stephenson (ed.), Teaching and Learning Online: Pedagogies for New Technologies, London: Kogan Page, 166-74.

Hine, C. (2000), Virtual Ethnography, London: Sage Publications Ltd.

Hughes, M. and Daykin, N. (2002), 'Towards constructivism: investigating students' perceptions and learning as a result of using an online environment', Innovations in Education and Teaching International, 39 (3), 217-24.

Kirkup, G. (2002), 'Identity, community and distributed learning', in M. Lea and K. Nicholl (eds), Distributed Learning: Social and Cultural Approaches to Learning, London: Routledge Falmer Press, 182-95.

Knight, P. (2002), Being a Teacher in Higher Education, Buckingham: SRHE/OUP.

Laurillard, D. (2002), 'Evidence based e-learning: what really works?', keynote presentation to the Alt Policy Board Meeting, 3 July, Aston University, Birmingham.

Land, R. (2000), 'Orientations to educational development', Educational Developments, 1 (2), 19-23.

Land, R. and Bayne, S. (2001), 'Screen or monitor? Issues of surveillance and disciplinary power in online learning environments', in C. Rust (ed.), Proceedings of the 2001 Ninth Improving Student Learning Symposium, Oxford: Oxford Centre for Staff and Learning Development, 125-38.

Lea, M. and Nicholl, K. (2002), Distributed Learning: Social and Cultural Approaches to Learning, London: Routledge Falmer Press. 
Loveless, A., Williams, C., and Kutnick, P. (2000), 'Evaluating teachers' use of portable computers in administration and the curriculum', paper presented at the British Educational Research Association Conference, Cardiff University, 7-10 September, http://www.leeds.ac.ukleducolldocuments/00001545.htm.

Lyotard, J. (1984), The Postmodern Condition: A Report on Knowledge, trans. Geoff Bennington and Brian Massumi, Manchester: Manchester University Press.

Macdonald, J. (2002), 'Developing competent e-learners: the role of assessment', paper presented at the Learning Communities and Assessment Cultures Conference, organized by the EARLI Special Interest Group on Assessment and Evaluation, University of Northumbria, 28-30 August, http://www.leeds.ac.ukleducol/documents/00002251.htm.

Oliver, M. (2002), 'What do learning technologists do?', Educational Developments, 3 (2), 19-21.

Prichard, C. and Willmott, $H$ (1997), 'Just how managed is the McUniversity?', Organisation Studies, 18 (2), 287-316.

Prosser, M. and Trigwell, K. (1999), Understanding Learning and Teaching, Buckingham: SRHE/ OUP.

Ramsden, P. (1992), Learning to Teach in Higher Education, London: Routledge.

Rowland, S. (2000), The Enquiring University Teacher, Buckingham: SRHE/OUP.

Salmon, G. (2000), E-moderating: The Key to Teaching and Learning Online, London: Kogan Page, http:lloubs.open. ac.ukle-moderatinglfivestep.htm.

Shulman, L. S. (1987), 'Knowledge and teaching: foundations of the new reform', Harvard Edicational Review, 57 (1), 1-22.

Slaouti, D. (2000), 'Student voices and course development: reading the signs on a distance course in educational technology', ALT-J, 9 (1), 62-72.

Taylor, R., Barr, J., and Steele, T. (2002), For a Radical Higher Education: After Postmodernism, Buckingham: SRHE/OUP.

Thorpe, M. (2002), 'Rethinking learner support: the challenge of collaborative online learning', Open Learning, 17 (2), 105-15.

Webb, G. (1996), Understanding Staff Development, Buckingham: SRHE/OUP.

Wenger, E. (1998), Communities of Practice: Learning, Meaning and Identity, Cambridge: Cambridge University Press.

Wills, S., Nouwens, F., Dixon, S. and Lefoe, G. (1997), 'Teaching at a distance about teaching at a distance: a resource for staff development', in Proceedings of the Fourteenth Annual Conference of the Australasian Society for Computers in Learning in Tertiary Education (ASCILITE), Curtin University of Technology: Academic Computing Services, http://www.ascilite.org.au/conferences/perth97/papers/Wills/Wills.html. 